\title{
LONG-TERM SAFETY OF BIOSIMILAR MEDICINAL PRODUCTS - KEY FOR ADMINISTRATION?
}

\author{
OCTAV GINGHINA ${ }^{1 \#}$, GEORGE TRAIAN ALEXANDRU BURCEA-DRAGOMIROIU ${ }^{2}$, BIANCA \\ GĂLĂȚEANU ${ }^{3 *}$, ARIANA HUDIȚA ${ }^{3}$, SILVIA DRAGOMIR $^{4}$, DOINA DRĂGĂNESCU ${ }^{5}$, ANDRA \\ BĂLĂNESCU ${ }^{6 \#}$, COSMIN ADRIAN ROȘCA $^{7 \#}$, CARMEN GIUGLEA $^{8 \#}$, DANIELA ELENA POPA $^{2}$, \\ ANCA PANTEA-STOIAN ${ }^{9 \#}$, CAROLINA NEGREI ${ }^{4}$ \\ ${ }^{I}$ Department of Surgery, "Sf. Ioan" Emergency Clinical Hospital, Faculty of Dental Medicine, "Carol Davila" University of \\ Medicine and Pharmacy, Bucharest, Romania \\ ${ }^{2}$ Departament of Drug Control, Faculty of Pharmacy, "Carol Davila" University of Medicine and Pharmacy, Bucharest, Romania \\ ${ }^{3}$ Department of Biochemistry and Molecular Biology, University of Bucharest, Romania \\ ${ }^{4}$ Departament of Toxicology, Faculty of Pharmacy, "Carol Davila" University of Medicine and Pharmacy, Bucharest, Romania \\ ${ }^{5}$ Departament of Pharmaceutical Physics and Informatics, Faculty of Pharmacy, "Carol Davila" University of Medicine and \\ Pharmacy, Bucharest, Romania \\ ${ }^{6}$ Department 5, Faculty of General Medicine, "Carol Davila" University of Medicine and Pharmacy, Bucharest, Romania \\ 7 Department of Drug Analysis, Faculty of Pharmacy, "Ovidius" University, Constanta, Romania \\ ${ }^{8}$ Department of Plastic and Reconstructive Surgery, "Sf. Ioan” Emergency Clinical Hospital, Faculty of General Medicine, \\ "Carol Davila" University of Medicine and Pharmacy, Bucharest, Romania \\ ${ }^{9}$ Departament of Diabetes, Nutrition and Metabolic Diseases, Faculty of General Medicine, "Carol Davila" University of \\ Medicine and Pharmacy, Bucharest, Romania
}

*corresponding author: bianca.galateanu@gmail.com

\#Authors with equal contribution

Manuscript received: July 2018

\begin{abstract}
The emergence of therapeutically effective biological agents has been a major breakthrough for the management of a wide range of chronic diseases with problematic, delayed or even lack of response to standard therapies, from psoriasis to atopic dermatitis, chronic urticaria, inflammatory bowel disease and rheumatoid arthritis. Biosimilar drugs are biological products as well, marketed as alternatives to the original biological medicine, whose safety and efficacy profile are very similar but not identical to the innovative biological medicinal product, which has already been authorised and placed on the market for 10 years or longer. In this review, we discuss complex issues such as the development of the biosimilar products, regulation aspects, safety and efficacy of biosimilar products as well as their use in clinical practice. Some extended reports are also addressed. By changing the context and providing a new option for mitigating increasing healthcare cost and improving the quality of life for more and more patients, biosimilar drugs are at the forefront of contemporary medicine.
\end{abstract}

\section{Rezumat}

Apariția agenților biologici eficienți terapeutic a reprezentat o descoperire majoră pentru gestionarea unei game largi de boli cronice problematice, întârziate sau chiar lipsite de răspuns la terapiile standard, de la psoriazis la dermatită atopică, urticarie cronică, boală intestinală inflamatorie și artrită reumatoidă. Medicamentele biosimilare sunt și produse biologice, comercializate ca alternative la medicina biologică originală, a căror profil de siguranță și eficacitate este foarte asemănător, dar nu identic cu medicamentul biologic inovator, care a fost deja autorizat şi introdus pe piață timp de 10 ani sau mai mult. În această lucrare se discută aspecte complexe, cum ar fi dezvoltarea produselor biosimilare, aspectele de reglementare, siguranța și eficacitatea produselor biosimilare, precum și utilizarea acestora în practica clinică. Sunt discutate și unele rapoarte extinse. Prin schimbarea contextului și prin oferirea unei noi opțiuni pentru diminuarea costurilor crescânde ale asistenței medicale și îmbunătățirea calității vieții pentru tot mai mulți pacienți, medicamentele biosimilare se află în fruntea medicinii contemporane.

Keywords: biological agents, biosimilars, safety and efficacy of biosimilar

\section{Introduction}

The emergence of therapeutically effective biological agents such as hormones, interferons, monoclonal antibodies, fusion proteins, cytokines, interleukins and vaccines has been a major breakthrough for the management of a wide range of chronic diseases with problematic, delayed or even lack of response to standard therapies, from psoriasis to atopic dermatitis, chronic urticaria, inflammatory bowel disease and rheumatoid arthritis $[1,2]$.

In use for over a decade now, the biological therapies have presented significant improvement not only of 
the therapeutic response but also of the patients quality of life with difficult to manage chronic diseases. In terms of their nature and structure, biological drugs are large, three-dimensional, therapeutically effective protein complexes developed by the expression of recombinant DNA in live cells or organisms as well, while their manufacture consists of a particularly complex biosynthesis process $[1,3]$. Despite their comparative great effectiveness, the cost of such products is both a major factor to consider from the patient's perspective and a policy issue of great importance worldwide. In this context, development of biosimilar drugs may represent a definitely more affordable alternative to expensive biological innovative agents already in use in clinical practice [4-8].

Biosimilar drugs are biological products as well, marketed as alternatives to the original biological medicine, whose safety and efficacy profile are very similar but not identical [9] to the innovative biological medicinal product, usually referred to as "reference" or "original" biological drug, which has already been authorised and placed on the market for 10 years or longer. In this context, the term "similarity" refers to the absence of clinically significant differences between the innovator and its biosimilar in terms of their purity, safety, or potency [10].

However, more widespread use of biosimilar medicines in clinical practice is not a straightforward issue and several factors have to be considered in that respect. First of all, the complexity of the biologicals manufacture, whether they are innovative or biosimilar, may inherently result in apparently minor structure variations even from one batch to the other of the same innovative biological, able, with time and lack of strict control, to produce clinical differences of relevance in terms of efficacy and safety [11-15].

In addition, as a result of confidentiality and trade secret issues for each pharmaceutical company (e.g., details related to manufacturing processes for authorised biologicals), potential biosimilar developers need to conduct careful and in-depth analysis of the original drug to establish their own distinct manufacturing process [16-20], a serious effort to undertake given the complexity of such processes.

Moreover, another factor that should not be overlooked as a potent barrier for biosimilar manufacture is the complexity of regulatory provisions for their marketing authorisation.

All the above, from design to manufacture, application for authorisation, actual placing on the market and post-marketing surveillance involve significant costs in terms of both money and time, all in the context of uncertain authorisation at the time when needed. Therefore, pharmaceutical companies select to develop biosimilars of innovative biologicals already providing larger sales and higher profits [9].

A further impediment to more widespread use of apparently more economical biosimilars in general clinical practice is the new and specific biopharmaceutical terminology, which adds to physicians' uncertainties, misunderstandings and misrepresentations about the use of biosimilars drugs, which requires more resolute action for a distinct and comprehensive understanding of specific terms related to the development process of biopharmaceuticals, innovative and biosimilar alike.

Relevant EU and US drug authorities have shared perspective on the definition of the biological drug, highlighting that the clinical outcome of the biosimilar is expected to be the same as that of the respective innovative, reference product [3].

As a central concept in the field of biopharmaceuticals, similarity in safety and efficacy between the reference and its biosimilar is stressed out as the core aspect to be demonstrated for a biosimilar to be authorised for use in clinical practice. Similarity is the appropriate term and not identity because of the intrinsic but strictly controlled natural variability characteristic to biological processes, absence of clinically significant differences between the two being keys for the minor inherent changes from one biological to another.

Even if the relationship between the biological product and its corresponding biosimilar is analogous to that of the original synthetic drug and its generic, biosimilar drugs are not considered generic [3, 21, 22]. At the same time, biosimilar drugs are not the same with either "biomimetic" drugs or "biocopies", which are intended, copies of monoclonal antibodies and fusion proteins, respectively, with no demonstrated bioequivalence with reference biological drugs. Unfortunately, some biomimetics have produced more adverse reactions and events than their reference $[10,14]$.

Generic drugs have small molecular chemical structure and are exact copies of their non-biological originals. Competent authorities require mandatory conduct of bioequivalence studies which, in the case of generics, must demonstrate similar pharmacokinetic and pharmacodynamic profiles between the generic synthesis [14] and the reference original, confirmed by a generic-reference bioequivalence ratio between 0.80 and 1.25 [10].

Bioequivalence studies carried out for biosimilar medicinal products aim to demonstrate the absence of clinically significant differences in biosimilar bioavailability compared to the reference biological product [10].

The success of biological therapies has also been enabled by the development of guidelines based on evidence of their use as well as achievement of a consensus on therapeutic goals. 
Though in agreement with their definition, relevant EU and US drug authorities have a different view on the interchangeability of the original biological drug and the biosimilar [10].

In fact, the FDA sees interchangeability as the possibility to substitute the biological for the reference drug without consulting the prescriber. Not only is the interchangeable product expected to have the same clinical outcome as the reference but its safety and reduced efficacy risk in case of inter-changeable to reference product switches and back in multiple administrations is closely evaluated. In terms of biological product to biosimilar switches, this translates into risk and effectiveness of alternative use between the two not outweighing the risk of using the reference medicine alone [4].

The above highlight the need for studies on the possibility of alternative use, in the form of clinical trials with specific design and types of data, able to determine the impact of such alternative use.

In Europe, the concept of interchangeability is not regulatory in nature but scientific and medical; in practice, interchangeability is demonstrated by the possibility of changing one drug with another of presumably the same clinical effect, which means replacing a biologic reference medicine with a biosimilar or replacing one biosimilar with another.

This substitution can be made either by switch to alternative treatment when the prescribing physician decides to change a drug for another intended for the same therapeutic purpose, or by automatic substitution, which refers to the practice of dispensing a drug in place of an equivalent and interchangeable other, at pharmacy level, and without prior consultation of the prescribing physician.

In this context, it should be noted that, in the EU, there is no harmonised position but Member States adopt their own, generally supporting reference biological drug/biosimilar or biosimilar/biosimilar interchangeability under the supervision of the prescribing physician, thus more and more insistently focusing on the need for specific interchangeability studies at EU level [23-29].

\section{Development of biosimilar products}

Biosimilar's similarity and not identity with their reference biological drugs contributes to concerns arising with regard to the former's safety and efficacy compared to the latter's. Each biosimilar product batch is structurally unique because of unavoidable post-translational changes known as the microheterogeneit [3], also displayed in original biologicals as well, as produced by biochemical changes and complex manufacturing process [15]. An instance of EMA accepted microheterogeneity for a biosimilar is the increased phosphorylation of mannose structures in epoetin alfa [21]. In this case, acceptability relies on that, in fact, the various phosphorylated structures are common forms of recombinant erythropoietin [21]. Microheterogeneity does not occur with generic drugs due to synthesis of their small chemical structures. Unlike generic drugs, which are chemically developed in compliance with an extremely predictable developmental process, biosimilars express unavoidable protein folding variability from one preparation to another, even in the case of identical primary protein sequences [3]. This is the result of the organic, unique nature of biological product synthesis in living organisms. Various alterations (e.g. phosphorylation and glycosylation) are induced during intracellular processing of the biosimilar, allowing the cell to protect the new protein during transportation to other cell compartments. Thus, information necessary on manufacture and marketing of biosimilars greatly exceeds that required for generic synthetic drugs, which are endowed with predictable characteristics. To be authorised, generic chemicals have to be shown to have similar pharmacokinetic profiles (bioequivalence) to the original chemical medicine, generally considered sufficient to establish therapeutic equivalence between original synthetic products and their generics. Unlike generics, marketing authorisation of biosimilars involves meticulous comparison with the reference biological, implying application of a whole range of methods, including performance of comparability exercises [21]. In order to identify potential differences from one protein to another, occurring in the finished biosimilar batch, an in-depth analysis is needed of the comparability of their structural and functional properties, as well as removal of process-related impurities [10], in a so-called "comparability exercise", which allows careful assessment by regulators of the quality, safety and efficacy of the "new" version resulting from the manufacturing process before final approval [15].

From the multitude of various analytical determinations used to establish the degree of structural similarity between the biosimilar and the reference product, the in vitro protein sequencing assay may be mentioned, as well as nuclear magnetic resonance spectroscopy and chromatography.

Fully aware of the inherent sequential variability from one finished biological product batch to the other and to establish batch comparability [22], manufacturers of biological drugs generally resort to such methods. Next, to identify any remaining variations not previously found in the in vitro molecular testing phase, preclinical testing is performed, undertaking a comparison between the pharmacokinetics and pharmacodynamics of the biosimilar to those of the reference product by testing on animal models [22]. The last step of the comparability exercise aims to determine the non-inferiority and similarity between the biosimilar product and the original biological and consists in clinical testing on healthy 
volunteers. In these studies, Phase II clinical trials are missing because the goal is to establish the absence of significant clinical differences between the biosimilar and the reference biological reference in terms of safety and efficacy $[3,22]$.

Complexity of variability issues increases in the case of manufacturing of biosimilar drugs by several manufacturers, with different quality systems.

In such situations, so-called drifts may occur, defined as "an unintended, unexplained, or unexpected trend of measured process parameter(s) and/or resulting product attribute(s) away from its intended target value in a time-ordered analysis over the lifetime of a process or product", manifesting as either systematic tendencies or abrupt deviations from the required quality parameters.

Product characteristics may drift from the acceptable range of similarity also in result of manufacturing process changes, known as product evolution [24].

Over time, the various patterns of drift and evolution may contribute to emergence of significant differences, even from one original biological drug batch to the other, from one region to another, as well as between reference biological drugs and their biosimilars, a cumulative phenomenon known as divergence [24]. Thus, when biosimilars and their reference are manufactured by different manufacturers, though initially similar, over time, the two may lose their similarity as a result of the manufacturer's noncorrection of drift or evolution of one or both products (reference and/or biosimilar) [24].

Significant clinical differences relevant for biosimilarity are potency, safety and immunogenicity profiles. For example, immunogenicity divergence of the biosimilar or reference biological product may affect the safety profile as well as treatment efficacy [24].

Divergence as a phenomenon can be managed by a firm monitoring of the quality system and by a strict measurement of process parameters [24].

\section{Regulatory-related issues}

Given that biosimilar and generic medicines do not belong to the same category, their regulations are separate and specific as well. Thus, while generics must be shown to be copies of their reference medicinal product, comprehensive and in-depth comparison with the reference biological product should be undertaken for biosimilars, confirming close similarity of biological features.

As use of biosimilar medicines is encouraged in the European Union, in 2005, in the context of elapse of the 10 -year period since the initial authorisation of the reference product for many biological medicines, epoetin alfa and somatropin included, the European Medicines Agency has developed the first regulatory guidelines for biosimilar medicines. The document provides for mandatory provision of evidence of the purity, efficacy and safety of biosimilars, as validated by clinical trials and extrapolation analysis [4]. EMA's efforts towards developing recommendations was taken a step further in 2006 , by preparation of guidelines for the authorisation of biosimilars, including issues related to the quality of analytical studies, as well as clinical and non-clinical aspects.

The developed guidelines aim to ensure the selection of appropriate biological reference products for each biosimilar, clear statement of methods and indications, submission of sufficient data to support biological activity, distinct and accurate account of pharmaco-physiological mechanisms as well as presence and feasibility of post-authorisation protocols for safety monitoring. In their revised form, EMA regulatory guidelines on biosimilar drugs include category-specific recommendations such as recombinant therapeutic proteins and monoclonal antibodies [4].

According to these guidelines, companies developing biosimilars need to put to use in-depth comparison with the reference biological to demonstrate that, despite the natural variability inherent to all biological medicines, the biosimilar proposed for authorisation is very similar to its reference, as well as the absence of clinically significant differences between the biosimilar and the reference biological product in terms of safety, quality and efficacy.

The EMA initiative has been continued by India, which, in 2012, also drafted guidelines for the management of biosimilar medicines, whereas US guidelines in this field were only drafted in January 2017 [22].

Even in an emerging regulatory frame, interchangeability is a growing concern for physicians, given the possibility for replacement of the original biological prescribed drug with a biosimilar by automatic substitution, thus rendering them unable to weigh the risks and benefits of the switch.

Compared to the generic medicine, the use of which instead of the original is a common practice nowadays, the immunogenicity risk (a medicinal product's ability to induce an immune response) in case of repeated substitution is particularly compelling for biopharmaceuticals [22].

Considering all the above, the European Medicines Agency allows competent authorities in EU Member States to decide on the matter themselves [16, 22], whereas the US has not yet developed regulatory provisions on how to determine the interchangeability of the original biological product with a biosimilar or between biosimilars, as currently there is no biosimilar in the US with FDA-approved interchangeability.

\section{Safety and efficacy}

Immunogenicity profiles of biological drugs are the highest priority, because they may compromise the safety and efficacy of the product. 
As already mentioned, repeated substitution of the original biological reference drug with its biosimilar product theoretically generates immunogenicity risk, but the same risk also occurs on switch from one original biological product batch to another.

Among factors contributing to outlining the immunogenicity profile of a biological one may mention product characteristics, underlying disease-specific processes, and individual, distinctive patient-related factors.

Because of the disease-specific processes and individual factors are under scrutiny since as early as the biological reference development process, the main immunogenicity component still in need of study development of the biosimilar are product characteristics. Therefore, inherent microheterogeneity of biosimilar structures, such as unique posttranslational modifications and protein aggregation, for instance, can have significant impact on immunogenicity [4].

As a result of confidentiality and trade secret issues for each pharmaceutical company (e.g., details related to manufacturing processes for authorised biologicals), after careful and in-depth analysis of the original drug, companies interested in the development of biosimilar products need to establish their own distinct manufacturing process [18].

Achieving biosimilarity depends on biosimilar developers' level of knowledge and expertise regarding development of biological drugs as well as on their ability to use the so-called reverse engineering [19]. However, even under such circumstances, inevitable post-translational changes during intracellular processing, generating microheterogeneity as compared to the reference biological are a cause of concern due to their immunogenicity inducing potential.

For improved confidence in their safety, medicinal products need to be monitored after actual placement on the market as well, thus allowing for complementation of information obtained through mandatory safety assessment and animal studies [20] in the pre-authorisation stage.

Here again, a comparison with the non-biological drug may prove useful. Standard protocols for applications for non-biological drug authorisation provide for preparation of a risk management plan addressing possible drug specific safety concerns, which is to be submitted to the competent authority for conducting the post-authorisation surveillance. However, for biosimilars that rarely induce immune responses, usually undetectable prior to approval of the application for authorisation, an expedited authorisation procedure may be applied, subject to mandatory conduct of a post-authorisation additional study, meant to identify potential adverse events [20].

In the European Union, the responsibility for assessment of all applications for marketing authorisation of biotechnology-manufactured biopharmaceuticals, most biosimilars included, lies with the European Medicines Agency, where actual assessment is carried out within the EMA scientific committees, with support from the Biologics Working Party and the Biosimilars Working Party.

Regulatory authorities in both the United States and the EU share their support for extrapolation to the biosimilar of indications of the original biological medicine, even in the absence of official studies on the respective indications. If biosimilarity is demonstrated (i.e., higher similarity of the two biological drugs, in terms of structure, biological activity, and efficacy, safety and immunogenicity profile), authorisation of the biosimilar may be considered justified by the safety- and efficacy-related experience already gained through use of the reference biological, which allows avoidance of unnecessary duplication of clinical trials and studies already carried out with the reference medicinal biological product.

Thus, a biosimilar used to treat a disease such as rheumatoid arthritis can also be authorised for the treatment of a different disease, such as psoriasis, without the need for a clinical trial, because the corresponding reference biological also has this indication.

The important thing for acceptance of such extrapolations is that applicants for biosimilar authorisation should clinically justify that their biosimilars are characterised by the same distribution, mechanism of action, pharmacokinetics, pharmacodynamics, efficacy and potential toxicity as the original biological medicinal products.

\section{Biosimilar drugs in clinical practice}

Despite the comparability of the biosimilars with their corresponding innovative product, healthcare professionals need to be aware of certain issues arising during development and authorisation of these products, highlighting problematic issues that need to be overcome in use of biosimilars [30].

One of the greatest challenges for biosimilar developers is to convince physicians to use biosimilars instead of their original biological correspondents, mainly deriving from physicians' concerns about the longterm safety of biosimilars, an aspect which may slow down the widespread adoption of biosimilars in therapeutic practice. The need to reduce this risk has even determined some organisations to engage in programs seeking to identify data able to permanently remove the reserves generated by such concerns.

Introduction of biologicals in the treatment of patients with psoriasis has meant an actual revolution in terms of therapeutic paradigms, allowing for control of the disease in many patients by means with acceptable safety profile. However, for most patients, access to biological medicines is limited by their high cost. 
Considering this aspect, introduction of biosimilars in the treatment of inflammatory diseases in recent years has evolved rapidly, which has allowed for the decrease of the cost therapy and, implicitly, improved the access to biologicals for patients with psoriasis.

Differences in approach of biosimilars from one competent authority to another as regards their definition, manufacture, authorisation, marketing and post-authorisation surveillance as well as the interchangeability of the original biologicals with their biosimilars emphasise the need for ensured traceability and pharmacovigilance for the collection of accurate data on adverse events occurring in patients with psoriasis. Globally, this process may be facilitated by spontaneous reporting, by creating registers and by using "big data".

Under the current conditions, with evident tendency to reduce dependence on the prescribing physician of therapeutic decisions involving biologicals, the International Psoriasis Council recommends to dermatologists, for example, to undertake an active role in developing policies for prescription of biosimilars in the setting of their healthcare facilities as well as by competent authorities [31].

Databases are created in this respect, recording patients, treatments given and reported adverse reactions, which allow for long-term safety assessment. Examples of such databases are those created in Denmark (DERMBIO) and the UK (BADBIR), which are an essential source of information for ongoing trials and studies.

Under the same aspect of long-term safety, here follow a few articles on long-term studies on biosimilars of certain molecules.

\section{Extended report}

In a randomized, double-blind, 52-week study, similar efficacy and safety have been demonstrated between SB4 (Benepali, Brenzys) and etanercept ETN in patients with rheumatoid arthritis (RA). In the open-label extension study, an efficacy, safety and long-term immunogenicity assessment was performed for continued treatment with SB4 as compared to switching from ETN to SB4 [32].

SB4 has been observed as effective and well tolerated for 2 years in RA patients. Efficacy, safety and immunogenicity have been comparable between the SB4/SB4 and the ETN/SB4 groups, and no risks have been associated with patient switch from ETN to SB4 [32].

In a study published by Abdalla et al. the goal wasoal of the study has been the assessment in real clinical setting of the efficacy and safety of an infliximab biosimilar in adult patients with inflammatory arthritis, transferred from treatment with the reference product. The study included patients admitted to the
Rheumatology Section of the Merlin Park University Hospital in Galway County, the first to introduce the infliximab biosimilar in patients with inflammatory rheumatic disease by transfer from treatment with the original infliximab. The study was initiated to substantiate long-term switch to alternative biosimilar treatment of all patients in Ireland with rheumatic diseases, thus improving access to biological therapies by $30 \%-50 \%$ lower costs. The findings of the study showed that, according to previous reports, in the 15.8-month follow-up period, patients switched from original infliximab therapy to biosimilar infliximab displayed comparatively similar efficacy and safety profiles, with no major safety issues [33].

Subsequently, in support of these results, larger studies of this therapeutic switch were also undertaken, with a longer follow-up period, and their results are pending [33].

The aim of a study performed by Goll et al. has been to assess the safety of the switch from treatment with original infliximab (Remicade ${ }^{\circledR}$, INX) to CTP13 (biosimilar infliximab, Remsima ${ }^{\circledR}$ ). The results have demonstrated the capacity of TNF inhibitors to improve the treatment of rheumatoid arthritis (AR), of spondylarthritis (SpA), psoriatic arthritis (PsA), Crohn's disease (CD), ulcerative colitis (UC), and chronic plaque psoriasis [34].

Recently there were published the results of another study, considered necessary because of the lack of real-life data on new biological reference and biosimilar drugs indicated in the treatment of moderate to severe plaque psoriasis [35].

According to the results of the study published in the British Journal of Dermatology, ustekinumab has been associated with the longest drug survival (the interval from introduction of the biological drug into therapy to its discontinuation/switch) among original biological and biosimilar drugs on the market for treatment of moderate to severe psoriasis. At the opposite end, the drug survival of secukinumab was found to be lowest, even when most secukinumab patients were not naive. Switch from the original to the biosimilar has not shown significant impact drug survival, and the safety profiles have proved comparable. Most commonly, adverse events occurred in secukinumab [35].

The results of the study justify the need for further research to assess long-term safety of new biological drugs in the treatment of psoriasis. The same research also undertook a comparison between the original biologicals adalimumab, etanercept, infliximab, secukinumab and ustekinumab in terms of safety, efficacy and drug survival. In addition, a comparison was conducted between the Benepali ${ }^{\circledR}$ biosimilar with the original etanercept (Enbrel ${ }^{\circledR}$, Amgen) and the Remsima ${ }^{\circledR}$ biosimilar with the original infliximab (Remicade ${ }^{\circledR}$, Janssen Biotech) [35]. 
Although associated with shorter drug survival, secukinumab was the drug administered in the largest number of patients achieving full remission from psoriasis plaque (PASI 100), but also with the most frequent adverse events (predominantly infections). At the same time, secukinumab also showed a slight increase in cardiovascular events compared to other drugs.

No difference has been found in drug survival between the original infliximab or etanercept and their biosimilars. Except for adalimumab and secukinumab, patients were generally given higher doses than recommended. In addition, safety profiles have proved comparable as well. The source of data used in this study has been the Danish DERMBIO registry, recording all patients in the country with moderate to severe psoriasis, monitored and treated with biological drugs from January to March 2007. On the study completion, it has included 2161 patients treated with adaliimumab (1332 patients), ustekinumab (1055 patients), etanercept (579 patients), infliximab (333 patients) and secukinumab (196 patients) [35]. The ADACCESS study (NCT02016105) is a controlled, randomized, double-blind, Phase III, controlled, 51week, clinical trial conducting a comparative efficacy and safety study between the Sandoz adalimumab biosimilar drug and the same company's reference biological medicinal product. The study was carried out on patients with moderate to severe forms of chronic, active, but clinically stable plaque psoriasis [36].

The investigation consisted of three treatment periods, as follows: the first 17 -week period involved randomisation of patients in groups receiving either the biosimilar adalimumab or its reference medicine; in the second phase, patients were re-randomised into four groups, the first two continuing their initial treatment and the other two switched to alternative treatment every six weeks until week 35 ; in the third study stage to week 51, patients were returned to their initially allocated treatment.

Study results showed that before week 51, the efficacy and safety of Sandoz's biosimilar adalimumab were similar to those of the reference biological. Disease response rates according to the PASI 75 (Psoriasis Area and Severity Index 75) in patients receiving biosimilar adalimumab throughout the study were $75.2 \%$ at week 17 and $84.5 \%$ at week 51 , as compared to $67.8 \%$ at week 17 and $79.6 \%$ at week 51 , in patients treated throughout with the reference medicine. Thus, the response according to PASI 75 shows at least $75 \%$ improvement of psoriasis severity. Disease response rates according to the Investigator's Global Assessment Index (IGA) as well were similar between the two study groups over the 51 study weeks. No clinically relevant differences between the two treatment groups acknowledged were in adverse events and the immunogenicity profiles were similar.
According to research findings, biosimilar drugs can fundamentally improve the ability of healthcare systems to address the challenge of price barriers for increased patient access to essential biological drugs, ensuring an actual alternative particularly for patients suffering from immunological diseases [36]. While informing about the study results, Sandoz representatives also announced the company's aim to develop 5 other biosimilar drugs from 2017 to 2020 [36].

Results of such studies converge to demonstrate that, as far as psoriasis is concerned at least, progress of biological therapies will change with the emergence of new anti-inflammatory targets for antibodies under development and accelerated emergence of biosimilar versions of existing antibodies whose data exclusivity expires.

To offset the pressure to lower biosimilar costs and their impact on drug affordability, awareness of the differences in efficacy triggered by the manufacturing process is important.

As more and more biosimilar drugs emerge, interchangeability between biosimilars and their original, as well as between two biosimilars of the same biological reference raises a central challenge in terms of their use in clinical practice, highlighting the urgent need for rigorous interchangeability studies.

At the same time, caution will also be needed in use of an increasingly extensive range of biosimilars, since switching from one drug to another may increase the immunogenicity risk, thereby neutralising drug efficacy.

An essential aspect in addition to effectiveness, which should not be overlooked, is the need for constant surveillance of biosimilar safety by means of specific pharmacovigilance actions.

\section{Conclusions}

By changing the context and providing a new option for mitigating increasing healthcare cost and improving the quality of life for more and more patients, biosimilar drugs are at the forefront of contemporary medicine.

Rising competition is accompanied by the potential to reduce the costs of associated healthcare and create a more accessible market for biological drugs. Currently, the innovative bio-better drugs are developed not only to imitate but also to improve the administration manner, mechanism of action, pharmacokinetics and pharmacodynamics of the reference biological [1]. However, with the influx of new biological therapeutic alternatives, it becomes increasingly necessary to develop analytical methods and tools with specific endpoints, capable to as convincingly as possible to demonstrate the similarity between the biosimilar and its reference medicine [4]. 
Moreover, in order to fully gain from the benefits of biosimilars, there is a critical need for active and indepth communication in the medical community to facilitate awareness and knowledge of both the safety and efficacy of biosimilars and their appropriate use in clinical practice.

Considering all that, the issue of biosimilar drugs is at the heart of active debates around the world, in the overall effort for careful evaluation for greater availability, efficacy and cost-effectiveness of these drugs.

Given the molecular complexity of biosimilar products, factors such as manufacturing reliability, structural similarity to the parent molecule, mechanism of action understanding level, the quality of pharmacodynamic assays applied, verified comparability of the pharmacokinetic and immunogenicity profiles, quality and quantity of clinical data used in studies, and the experience with the parents' product of the original drug manufacturer should be carefully weighed in the process undertaken for biosimilar marketing authorisation.

Nowadays, when the decision on interchangeability is still a matter of debate, automatically substituting the original product with the biosimilar independently from the prescriber does not appear appropriate as it is vital for the patient's safety that the physician should be aware of potential differences between the reference biological drug and its biosimilar as well as of the implications of such differences on safety and efficacy. To make informed decisions, doctors need comprehensive and in-depth information on both the biosimilar and the innovative drug.

At the same time, pharmacovigilance issues are equally important for identifying potential safety and efficacy issues arising from biosimilar use.

In addition, regulatory provisions for naming and labelling of biosimilar products should be the responsibility of a single body authorised in that respect, able to impose recognition and acceptance at international level.

Under the current conditions, despite increasing the introduction of biosimilar products on the global pharmaceutical market, the ability of manufacturers to consistently comply with quality standards over longer terms is still a matter requiring indisputable proof.

Lastly but not least, in spite of developing European legislation on assessment and marketing authorisation of biosimilar products, regulatory guidelines developed so far can only be used as a roadmap, only pointing to problematic areas requiring further research and monitoring. Therefore, as research continues to yield more extensive results, authorisation of biosimilar products increasingly seems to be a matter of caseby-case decision.

\section{References}

1. Epstein MS, Ehrenpreis ED, Kulkarni PM, FDARelated Matters Committee of the American College of Gastroenterology. Biosimilars: the need, the challenge, the future: the FDA perspective. Am J Gastroenterol., 2014; 109(12): 1856-1859.

2. Burcea-Dragomiroiu GTA, Popa DE, Velescu B, Andrie A, Ordeanu V, Nicolae AC, Drăgoi CM, Bârcă M, Ginghină $\mathrm{O}$, Synthesis, characterization and microbiologicalactivity evaluation of novel hard gelatine capsules with cefaclor and piroxicam. Farmacia, 2016; 64(6): 887-895.

3. Kefalas $\mathrm{CH}$, Ciociola AA, FDA-Related Matters Committee of the American College of Gastroenterology. The FDA's generic-drug approval process: similarities to differences from brand-name drugs. $A m ~ J$ Gastroenterol., 2011; 106(6): 1018-1021.

4. Camacho LH, Frost CP, Abella E, Morrow PK, Whittaker S. Biosimilars 101.

5. Blackstone E, Fuhr J, The economics of biosimilars. Am Health Drug Benefits, 2013; 6(8): 469-478.

6. Silver S. Industry Surveys: Biotechnology. Standard \& Poor's; 2013 (available at: https://securingalpha. files.wordpress.com).

7. Dorey E, How the biologics landscape is evolving. Clin Pharm., 2014; 6(9): 1-6.

8. Seston EM, Ashcroft DM, Griffiths CE, Balancing the benefits and risks of drug treatment: a statedpreference, discrete choice experiment with patients with psoriasis. Arch Dermatol., 2007: 143: 1175-1179.

9. FDA. Alefacept, Amevive, Biogen, Inc. - package insert, http://www.fda.gov.

10. Dorner T, Kay J, Biosimilars in rheumatology: current perspectives and lessons learnt. Nat Rev Rheumatol., 2015; 11(12): 1-12.

11. Schellekens $H$, The first biosimilar epoeitin: but how similar is it?. Clin J Am Soc Nephrol., 2008; 3(1): 174-178.

12. Mysler E, Scheinberg M, Biosimilars in rheumatology: a view from Latin America. Clin Rheumatol., 2012; 31(9): 1279-1280.

13. Castañeda-Hernández G, González-Ramírez R, Kay $\mathrm{J}$, Scheinberg MA, Biosimilars in rheumatology: what the clinician should know. RMD Open, 2015; 1(1): 1-7.

14. US Food Administration. Guidance for Industry: Bioequivalence studies with pharmacokinetic endpoints for drugs submitted under an ANDA. www.fda.gov.

15. U.S. Food Administration. Draft Guidelines: Nonproprietary Naming of Biological Products. www.fda.gov.

16. NCSL. State Laws and Legislation Related to Biologic Medications and Substitution of Biosimilars. National Conference of State Legislature; 2014. www.ncsl.org.

17. Puig L, Biosimilars in dermatology: Starting with infliximab. Actas Dermosifiliogr., 2013; 104(3): 175-180.

18. Graser D. Industry voices: biosimilars and trade secrets. FierceBiotech; 2012. www.fiercebiotech.com.

19. Socinski M, Curigliano G, Jacobs I, Gumbiner B, MacDonald J, Thomas D, Clinical considerations 
for the development of biosimilars in oncology. MAbs., 2015; 7(2): 286-293.

20. Weise M, Bielsky MC, De Smet K, Ehmann F, Ekman N, Giezen TJ, Gravanis I, Heim HK, Heinonen E, Ho K, Moreau A, Narayanan G, Kruse NA, Reichmann G, Thorpe R, van Aerts L, Vleminckx C, Wadhwa M, Schneider CK, Biosimilars: what clinicians should know. Blood, 2012; 120(26): 5111-5117.

21. Weise M, Kurki P, Wolff-Holz E, Bielsky MC, Schneider C, Biosimilars: the science of extrapolation. Blood, 2014; 124(22): 3191-3196.

22. European Medicines Agency. European Assessment Report on Binocrit. www.ema. europa.eu.

23. Gupta V, Khaitan BK, Therapeutic potential of biosimilars in dermatology. Ind J Dermatol Venereol Leprol., 2015; 81(5): 451-456.

24. Sârbu MI, Tampa M, Matei C, Mitran CI, Mitran MI, Piţuru S, Pop CS, Şaramet G, Georgescu SR, Infliximab biosimilar versus methotrexate for the treatment of moderate to severe psoriasis. Farmacia, 2018, 65(5): 962-967.

25. Ramanan S, Grampp G, Drift, evolution, and divergence in biologics and biosimilars manufacturing. BioDrugs, 2014; 28(4): 363-372.

26. Popa L, Negrei C, Neagoe IV, Albulescu L, Preoteasa V, Bălănescu AR, Ghica MV, Manda G, Proinflammatory signal delivered in vitro by leflunomide active metabolite a77 1726 on abnormal peripheral monocytes in rheumatoid arthritis. Farmacia, 2010; 58(5): 546-558.

27. Mayden KD, Larson P, Geiger D, Watson H, Biosimilars in the United States: considerations for oncology advanced practitioners. J Adv Pract Oncol., 2015; 6(2): 108-116.

28. WHO. Guidelines on Evaluation of Similar Biotherapeutic Products (SBPs); 2009. www.who.int.
29. Jelkmann W, Biosimilar epoetins and other "followon" biologics: update on the European experiences. Am J Hematol., 2010; 85(10): 771-780.

30. Mellstedt $\mathrm{H}$, Niederwieser D, Ludwig $\mathrm{H}$. The challenge of biosimilars. Ann Oncol., 2008; 19(3): 411-419.

31. Questions and answers on recommendation for refusal of marketing application for Alpheon. London, UK: European Medicines Agency, 2006. www.emea.europa.

32. Emery P, Vencovský J, Sylwestrzak A, Leszczyński P, Porawska W, Stasiuk B, Hilt J, Mosterova Z, Cheong SY, Ghil J. Long-term efficacy and safety in patients with rheumatoid arthritis continuing on SB4 or switching from reference etanercept to SB4. Ann Rheum Dis., 2017; 76: 1986-1991.

33. Abdalla A, Byrne N, Conway R, Walsh T, Mannion G, Hanly M, O'Sullivan M, Curran AM, Carey JJ, Long-term safety and efficacy of biosimilar infliximab among patients with inflammatory arthritis switched from reference product. Open Access Rheumatology: Research and Reviews, 2017; 9: 29-35.

34. Goll GL, Jørgensen KK, Sexton J, Olsen IC, Bolstad N, Lorentzen M, Haavardsholm EA, Mork C, Jahnsen J, Kvien TK, Long-Term Safety and Efficacy of Biosimilar Infliximab (CT-P13) after Switching from Originator Infliximab: Results from the 26-Week Open Label Extension of a Randomised Norwegian Trial (NOR-SWITCH). Arthritis Rheumatol., 2017; 69(suppl 10).

35. Egeberg A, Ottosen MB, Gniadecki R, Broesby-Olsen S, Dam TN, Bryld LE, Rasmussen MK, Skov L, Safety, efficacy and drug survival of biologics and biosimilars for moderate-to-severe plaque psoriasis. British J Dermatol., 2018; 178(2): 509-519.

36. https://clinicaltrials.gov. 